
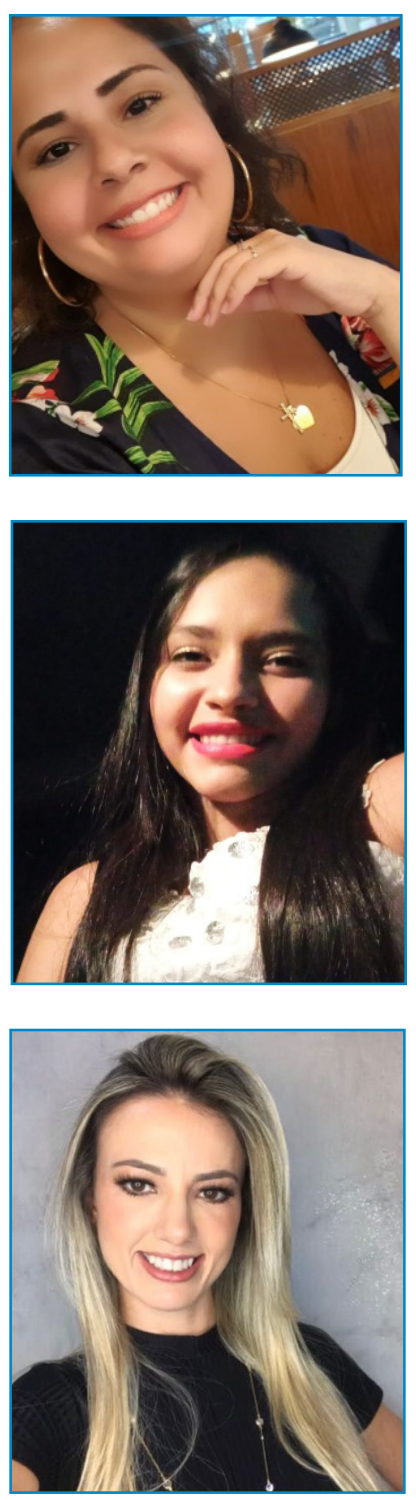

\section{O CENÁRIO DAS LIGAS ACADÊMICAS DE ESTOMATERAPIA NO BRASIL}

\section{THE SCENARIO OF ACADEMIC STOMATHERAPY LEAGUES IN BRAZIL
EL ESCENARIO DE LAS LIGAS ACADÉMICAS DE ESTOMATERAPIA EN BRASIL

\section{Adriana Bispo Alvarez ${ }^{1, *}$, (D) , Cicera Clareliz Gomes Alves² (DD , Viviane Mamede Vasconcelos Cavalcante ${ }^{3}$ (D)}

A busca pelo aprofundamento em áreas específicas tem crescido substancialmente na formação profissional, com o intuito de investigar e compartilhar conhecimentos, em conjunto com a participação ativa em atividades práticas, de modo a preservar a indissociabilidade do tripé ensino-pesquisa-extensão ${ }^{1}$. Por meio dessa percepção, adotaram-se estratégias que promovessem imersão e articulação do conhecimento entre teoria e prática, mediante a criação de Ligas Acadêmicas (LA), que consistem em organizações caracterizadas por estatuto próprio, isenta de fins lucrativos, compostas por acadêmicos e orientadas por profissionais integrantes de determinadas instituições, de forma extracurricular.

As LA têm, no escopo, o compromisso com a sociedade regulamentado pela Lei de Diretrizes e Bases da Educação Nacional (LDB), que estabelece como finalidade do ensino superior o compromisso social das universidades representado na forma de prestação de serviços especializados à comunidade, de modo que estabeleça essa relação de reciprocidade ${ }^{2}$. Nessa perspectiva, com as propostas de curricularização da extensão nas diretrizes de formação de enfermeiros, as LA serão estratégias para envolver alunos no mundo da estomaterapia, tão superficialmente discutida na formação de enfermeiros.

No Brasil, desde 1920, as LA estão vinculadas historicamente aos cursos de Medicina, porém há incipientes produções científicas acerca da temática. Embora esteja posta a relevância na formação acadêmica, a busca de espaço e implementação dessas organizações na grade curricular ainda é um desafio ${ }^{3}$. Além de contribuir para o saber-pensar e o saber-fazer de estudantes ainda na Universidade, empoderando-os no processo formativo, a LA possibilita a problematização e, posterior, transformação da realidade baseadas nas demandas regionais.

No contexto da enfermagem em estomaterapia, existe iniciativa da Sociedade Brasileira de Estomaterapia (SOBEST) para registro das LA, que estão diretamente vinculadas ao departamento de educação, cujo objetivo é fornecer visibilidade e envolver os acadêmicos, ainda no contexto da graduação, na estomaterapia. Atualmente, tem-se dez Ligas com registro: Universidade Federal do Rio de Janeiro (Campus Macaé), Universidade Federal

\footnotetext{
1.Universidade Federal do Rio de Janeiro - Centro Multidisciplinar UFRJ-Macaé - Instituto de Enfermagem - Macaé (RJ), Brasil.

2.Universidade Regional do Cariri - Faculdade de Enfermagem - Crato (CE), Brasil.

3.Universidade Federal do Ceará - Faculdade de Farmácia, Odontologia e Enfermagem - Departamento de Enfermagem - Fortaleza (CE), Brasil.

*Autora correspondente: bispo.alvarez@gmail.com

Como citar: Alvarez AB, Alves CCG, Cavalcante VMV. O cenário das ligas acadêmicas de estomaterapia no Brasil. ESTIMA, Braz. J.

Enterostomal Ther., 2021, 19: e2121. https://doi.org/10.30886/estima.v19.1105_PT
} 
do Ceará, Universidade Federal São João Del-Rei (Campus Centro-Oeste Dona Lindu), Universidade Estadual do Ceará, Universidade Regional do Cariri, Universidade Federal do Maranhão, Universidade Estadual do Piauí, Escola de Enfermagem da Universidade de São Paulo, Pontifícia Universidade Católica de Minas Gerais - Coração Eucarístico e Liga Acadêmica de Estomaterapia e Tecnologias (LAET) da Universidade Federal do Piauí.

Ao considerar que as LA são entidades de extrema importância para formação de excelência, faz-se necessário o apoio de profissionais que estejam atualizados sobre a área e tenham propriedade comprovada para ensinar e discorrer sobre os três pilares da estomaterapia e, por esse motivo, mostra-se a importância das LA de estomaterapia se credenciarem à SOBEST, visto que os profissionais qualificados da área da estomaterapia estão vinculados a essa associação, de modo a oferecer melhor suporte no processo de desenvolvimento das LA.

Ademais, tem-se, ainda, como aspecto positivo em relação ao credenciamento, a possibilidade de divulgação das atividades desenvolvidas por uma LA por meio das Redes Sociais da SOBEST, certificação para membros integrantes e participação direta nos eventos da SOBEST a fim de evidenciar excelência das atividades e eventos promovidos pela LA registrada.

Dessa forma, espera-se que iniciativas de criação e implementação das LA, além de registro na SOBEST, sejam motivadas e replicadas para que possam constituir atividades fundamentais para a disseminação do conhecimento sobre a estomaterapia no Brasil, contribuindo no processo formativo e impactos positivos para futuros estomaterapeutas e, consequentemente, com implicações para o cuidado das pessoas com feridas, estomias ou incontinências e para as instituições de saúde.

\section{REFERÊNCIAS}

1. Panobianco MS, Borges ML, Caetano EA, Sampaio BAL, Magalhães PAP, Moraes DC. A contribuição de uma liga acadêmica no ensino de graduação em enfermagem. Rev Rene. 2013 [citado 03 abr 2021]; 14(1):169-78. Disponível em: http:// periodicos.ufc.br/rene/article/view/3351/2589

2. Lei n. 9.394 de 20 de dezembro de 1996 (BR). Estabelece as diretrizes e bases da educação nacional. Diário Oficial da União [periódico na internet], Brasília (DF). 23 dez 1996 [citado 03 abr 2021]. Disponível em: http://www.planalto.gov.br/ ccivil_03/leis/19394.htm

3. Vieira $C B$, Silva DA. Contribuições de uma liga acadêmica do trauma e emergência na formação universitária: percepção dos integrantes. Revista Nursing. 2009 [citado em 03 abr 2021]; 22(259):3384-8. Disponível em: http://www.revistanursing. com.br/revistas/259/pg26.pdf 